\title{
Melatonin and Other Tryptophan Metabolites Produced by Yeasts: Implications in Cardiovascular and Neurodegenerative Diseases
}

\author{
Ruth Hornedo-Ortega ${ }^{1}$, Ana B. Cerezo ${ }^{1}$, Ana M. Troncoso ${ }^{1}$, M. Carmen Garcia-Parrilla ${ }^{1}$ \\ and Albert Mas ${ }^{2 *}$
}

${ }^{1}$ Facultad de Farmacia, Universidad de Sevilla, Sevilla, Spain, ${ }^{2}$ Facultad de Enología, Universitat Rovira i Virgili, Tarragona, Spain

OPEN ACCESS

Edited by:

Enrica Pessione,

University of Turin, Italy

Reviewed by:

Robin Anderson

United States Department of Agriculture/Agricultural Research

Service, USA

Paul Richard Himes,

University of Louisville, USA

${ }^{*}$ Correspondence:

Albert Mas

albert.mas@urv.cat

Specialty section:

This article was submitted to

Systems Microbiology,

a section of the journal

Frontiers in Microbiology

Received: 20 October 2015 Accepted: 27 December 2015

Published: 19 January 2016

Citation:

Hornedo-Ortega R, Cerezo $A B$, Troncoso AM, Garcia-Parrilla MC and Mas A (2016) Melatonin and Other Tryptophan Metabolites Produced by Yeasts: Implications in Cardiovascular

and Neurodegenerative Diseases.

Front. Microbiol. 6:1565.

doi: 10.3389/fmicb.2015.01565
Yeast metabolism produces compounds derived from tryptophan, which are found in fermented beverages, such as wine and beer. In particular, melatonin and serotonin, may be relevant due to their bioactivity in humans. Indeed, the former is a neurohormone related to circadian rhythms, which also has a putative protective effect against degenerative diseases. Moreover, serotonin is a neurotransmitter itself, in addition to being a precursor of melatonin synthesis. This paper summarizes data reported on fermented beverages, to evaluate dietary intake. Additionally, the article reviews observed effects of yeast amino acid metabolites on the prevention of neurodegenerative diseases (Alzheimer's and Parkinson's) and angiogenesis, focusing on evidence of the molecular mechanism involved and identification of molecular targets.

Keywords: wine, beer, VEGF, $\beta$-amyloid, $\alpha$-synuclein, tryptophol, serotonin

\section{ORIGIN, OCCURRENCE, AND DIETARY INTAKE}

The presence of bioactive compounds in fermented beverages has long been observed and they have been studied with great interest. A large body of research has focused on polyphenols, in particular, since these bioactive compounds are already present in plants and released into fermented products. Yeast also transforms certain other molecules into biologically active compounds. Among these, the case of amino acid tryptophan is of interest, since it is the precursor of at least three biologically active compounds: melatonin, serotonin, and tryptophol (Mas et al., 2014).

Tryptophol is an alcohol produced by the Ehrlich pathway and it has long been detected in appreciable concentrations in wines and beers in the mg/L range (Bartolomé et al., 2000; Monagas et al., 2007). Therefore, its occurrence in beverages is widely recognized. Moreover, tryptophol has also been indicated as a quorum sensing molecule for yeast (Sprague and Winans, 2006).

Just a few years ago, melatonin was detected in wines in much lower levels: within the ng/L range. Not only was it evidenced in wines, but also in other fermented foods, as summarized in Table 1. Furthermore, Rodriguez-Naranjo et al. (2011) highlighted that melatonin was produced after alcoholic fermentation, pinpointing the role Saccharomyces plays. Indeed, different strains synthetized melatonin at different levels (Rodriguez-Naranjo et al., 2012).

The synthetic pathway of melatonin in yeast is not completely elucidated, yet it seems the formation of serotonin might be an intermediate in the pathway (Mas et al., 2014). In addition, serotonin has been detected at $\mathrm{mg} / \mathrm{L}$ levels in red wine following malolactic fermentation (Wang et al., 2014). Further research is required to explore the roles of yeast and bacteria in the occurrence of these bioactive compounds in fermented products. 
One of the characteristics of bioactive compounds is the minimal concentration required for them to act. The reported concentrations in wine and beer would mean that someone consuming these beverages would obtain a low daily intake of these compounds. According to WHO, the daily intake of ethanol should not exceed $30 \mathrm{~g}$ and $20 \mathrm{~g}$ for men and women, respectively. That is to say that daily intake for a man of a wine can provide up to $0.00005-0.13 \mathrm{mg}$ of melatonin. In a comprehensive review summarizing the results of human intervention studies, Harpsøe et al. (2015) concluded that the bioavailability of melatonin was $15 \%$. In our example, its bioavailable concentration should result in $1.5-4000 \mathrm{pg} / \mathrm{mL}$ of melatonin in blood. Physiological values for day plasma melatonin are very low, accounting for several $\mathrm{pg} / \mathrm{mL}(5-$ $10 \mathrm{pg} / \mathrm{mL}$ in human plasma) (de Almeida et al., 2011). Thus, $\mathrm{pg} / \mathrm{mL}$ in plasma might be expected after dietetic intake of wine or beer, considering the values displayed in Table 1 . Indeed, Maldonado et al. (2009) determined an increase in the concentration of plasmatic melatonin after the ingestion of a moderate dose of beer $(330 \mathrm{~mL}$ for women volunteers, $660 \mathrm{~mL}$ for men). To the best of our knowledge, there is no published data on the bioavailability of serotonin after food or beverage intake.

\section{BIOLOGICAL EFFECTS AND PREVENTION OF CHRONIC DISEASES}

Literature on the biological effects of these compounds is extensive and encompasses circadian rhythm, antioxidant properties, and reproductive function. Due to the length of this mini-review, we will focus on more recent findings on the prevention of the most prevalent degenerative diseases, such as cancer, and cardiovascular and neurodegenerative diseases.

\section{IMPLICATIONS FOR CANCER AND CARDIOVASCULAR DISEASE: THE ROLE OF ANGIOGENESIS}

Angiogenesis, which consists of the formation of new blood vessels from pre-existing ones, is crucial for organ growth during embryonic development and after birth. However, in adulthood, angiogenesis plays an essential role in the pathogenesis of diverse chronic diseases, such as cancer and cardiovascular disease, involving the progression and development of the tumor, and development and destabilization of atherosclerotic plaques (Celletti et al., 2001; Bergers and Benjamin, 2003).

Angiogenesis occurs when there is an imbalance between pro-angiogenic (e.g., vascular endothelial growth factor (VEGF), basic fibroblast growth factor, alfa tumor necrotic factor, etc.) and anti-angiogenic (e.g., angiostatin and endostatin) factors. VEGF is the most active endogenous pro-angiogenic factor in humans (Giles, 2001; Dulak, 2005; Cebe-Suarez et al., 2006; Cook and Figg, 2010). It exerts its angiogenic effect by stimulating VEGF receptor 2 (VEGFR-2), which is critical for promoting the proliferation and differentiation of endothelial cells (Giles, 2001; Ferrara and Kerbel, 2005). It has been demonstrated that VEGF promotes atherosclerotic plaque progression (Celletti et al., 2001; Khurana et al., 2005) and tumor angiogenesis (Senger et al., 1993). Indeed, VEGF is a target for drug therapies that aim to

TABLE 1 | Concentration of melatonin and other tryptophan metabolites in fermented products.

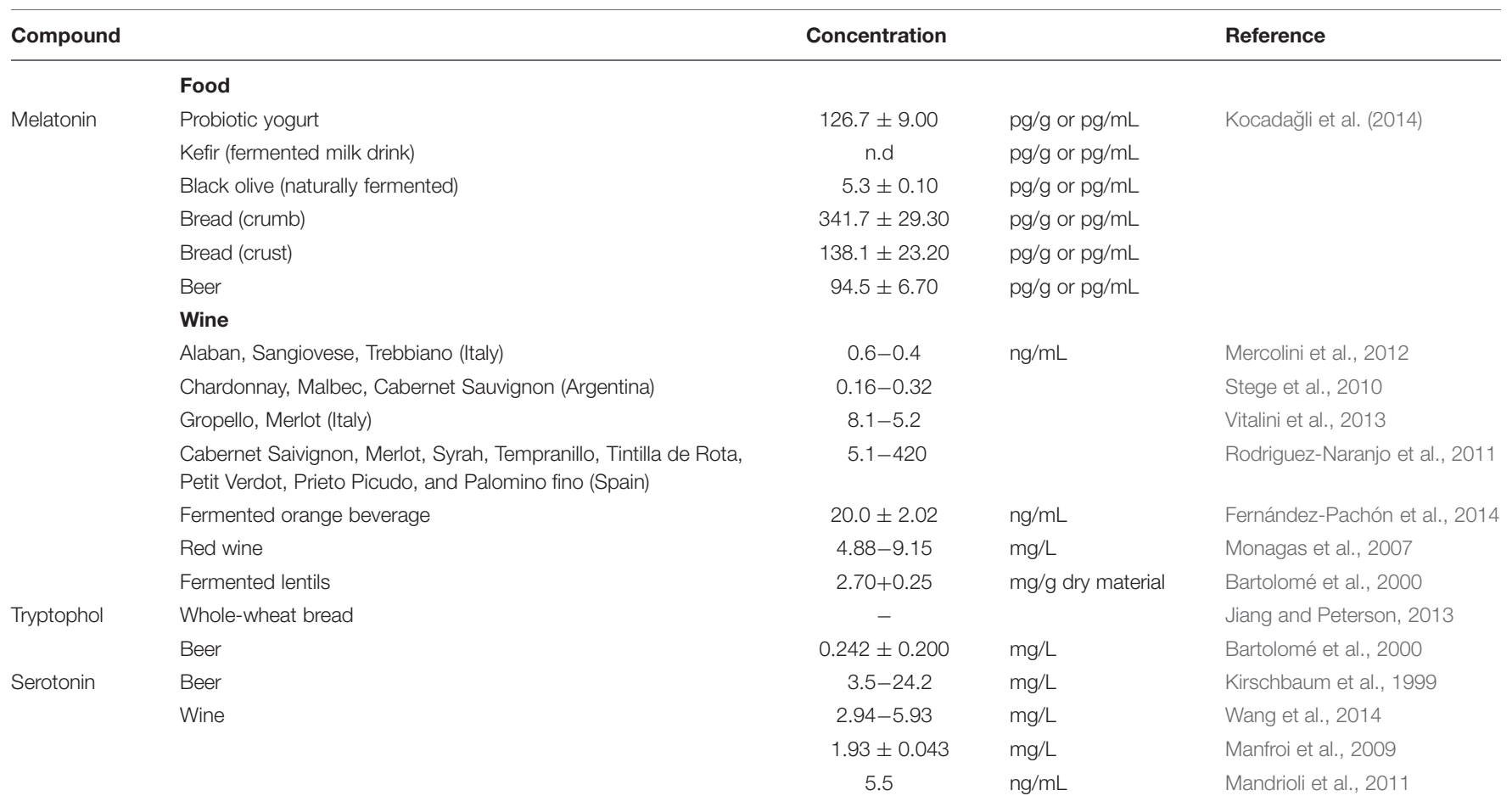


inhibit VEGF signaling (Ferrara and Kerbel, 2005). Anti-VEGF antibodies, aptamers and small molecule VEGFR tyrosine kinase inhibitors have been developed and given regulatory approval for the treatment of colon, lung, breast, kidney, and liver cancer, in addition to neovascular age-related macular degeneration (Giles, 2001; Ferrara and Kerbel, 2005). However, serious side effects, such as hypertension, have been reported with prolonged use of anti-VEGF therapies (Zhu et al., 2007; Wu et al., 2008; Kappers et al., 2010). The use of natural products in reducing VEGFinduced angiogenesis may prove to be more beneficial than the current anti-VEGF drugs available (Moyle et al., 2015).

Melatonin has been associated with a decline in VEGF secretion levels in the serum of advanced cancer patients (Lissoni et al., 2001), in addition to markedly reducing the expression of VEGF in HUVEC and culture cancer cells at $1 \mu \mathrm{M}$ and $1 \mathrm{mM}$ (Dai et al., 2008; Cui et al., 2012; Álvarez-García et al., 2013; Gonçalves et al., 2014). Melatonin has also been proven to reduce endothelial cell proliferation, invasion, migration, and tube formation, through downregulation of VEGF at $1 \mathrm{mM}$ (Álvarez-García et al., 2013). The possible cell signaling pathway when melatonin inhibits HUVEC proliferation has been related to the following pathway: melatonin receptors/ERK/PI3K/Akt/PKC/NF-kB (Cui et al., 2008). Additionally, Sohn et al. (2015) have recently demonstrated that melatonin $(1 \mathrm{mM})$ upregulates miRNA3195 and miRNA374b, whose overexpression synergistically reduced VEGF production in hypoxic PC-3 prostate cancer cells, indicating the important role of miRNA3195 and miRNA374b in melatonin induced antiangiogenic activity. Melatonin $(40 \mathrm{mg} / \mathrm{kg})$ has also shown an antitumor effect on mammary tumor growth in mice after 21 days of treatment; the mice displayed significantly smaller tumor volume and tumor regression (Jardim-Perassi et al., 2014). Additionally, in the same study, a lower expression of VEGFR2 was observed in the melatonin-treated tumors compared to the vehicle-treated tumors. More research is consequently needed to focus on determining the molecular mechanism by which melatonin exerts its angiogenic effect and the molecular target involved.

\section{NEURODEGENERATIVE DISEASES}

Alzheimer's disease (AD) and Parkinson's disease (PD) are the most common human neurodegenerative diseases. In both cases, their incidence increases with age. The aggregation of proteins that results in different fibrillar structures is responsible for these disorders. Specifically, they are owing to the abnormal pathological assembly of amyloid- beta $(\mathrm{A} \beta)$, tau and $\alpha$-synuclein $(\alpha \mathrm{S})$.

Indeed, several studies have demonstrated that protofibrils and oligomers of $\alpha \mathrm{S}$ and $\mathrm{A} \beta$ are more neurotoxic than fibrils (Pike et al., 1993; Lashuel et al., 2002; Volles and Lansbury, 2003; Outeiro et al., 2008).

This review focus on the evidence of certain bioactives which can present in fermented products. However, to give a fair balance, alcohol effects on neurodegeneration have to be highlighted as it is a major component formed by yeast in alcoholic beverages. It is well-Known that alcohol intake crosses the $\mathrm{BBB}$ (Blood-Brain Barrier) easily producing the excessive release of neurotransmitters, oxidative stress and inflammatory response which turns out in neurotoxicity and finally cell death. (Persidsky and Potula, 2014).

\section{ALZHEIMER'S DISEASE}

Alzheimer's disease is a progressive and irreversible neurodegenerative disorder characterized by loss of memory and cognition, abstract thinking, and personality alteration. The etiology of $\mathrm{AD}$ is unknown in more than $90 \%$ of cases. In the pathogenesis of $\mathrm{AD}$ there are two principal hallmarks: neurofibrillary tangles (NFTs) and amyloid plaques. NFT are formed by the intracellular accumulation of phosphorylated tau protein and amyloid plaques, by extracellular accumulation of amyloid $\beta$ peptides (Hardy and Selkoe, 2002). The amyloid beta peptide is formed via cleavage of the amyloid precursor protein (APP). In the non-amyloidogenic pathway (normal state), APP is cleaved by $\alpha$-secretase, to generate sAPP (soluble $\mathrm{N}$ - terminal fragment), which is neuroprotective as it is involved in the enhancement of synaptogenesis, neurite outgrowth, and neuronal survival. Conversely, in the disease state, APP is cleaved by $\beta$ and $\gamma$ secretase, resulting in insoluble beta amyloid peptide, which has high potential for assembly and formation of toxic aggregates (Gandy, 2005).

Several mechanisms have been proposed to explain $\beta \mathrm{A}$ neurotoxicity, such as oxidative stress and loss of endogenous antioxidants (Behl et al., 1994; Abramov and Duchen, 2005; Hamel et al., 2008); mitochondrial damage, depolarization, and mitochondrial permeability transition pore opening (Moreira et al., 2001, 2010; Abramov et al., 2004, 2007); destabilization of intracellular calcium homeostasis in neurons (Bezprozvanny and Mattson, 2008); glial cells (Abramov et al., 2003, 2004), and neuroinflammation (McNaull et al., 2010).

Levels of melatonin and its precursors (serotonin and tryptophan) are significantly decreased in elderly AD individuals and are associated with the emergence of AD (Zhou et al., 2003; Greilberger et al., 2010). A growing body of evidence supports the protective role of melatonin in several molecular mechanisms implicated in the development of AD.

Among these mechanisms, the most significant one is that melatonin prevents amyloid aggregation and overproduction. This neurohormone has a great affinity for $\mathrm{A} \beta$ peptide, preventing amyloid fibril formation (Masilamoni et al., 2008), as determined by circular dichroism (CD) spectroscopy, electron microscopy, nuclear magnetic resonance (NMR) and electrospray ionization-mass spectrometry (ESI-MS). In particular, a hydrophobic interaction has been observed between melatonin and $A \beta$, specifically on the 29-40 residues of the A $\beta$ segment (Skribanek et al., 2001). Additionally, melatonin has inhibitory effects on the formation of secondary $\beta$-sheet structures through the disruption of the histidine $\left(\mathrm{His}^{+}\right)$and aspartate $\left(\mathrm{Asp}^{-}\right)$salt bridges in $\mathrm{A} \beta$ peptide that promote fibril dissolution (Fraser et al., 1991; Huang et al., 1997; Pappolla et al., 1998). 
Melatonin presents a great capacity to regulate the synthesis and maturation of APP at different levels by: decreasing its mRNA encoding $\beta$-APP (Song and Lahiri, 1997; Lahiri, 1999); blocking CAMP production, which is involved in activating the APP gene promoter, (Husson et al., 2002); and inactivating GSK3 , which promotes $\alpha$-secretase mediated cleavage of APP, favoring the non-amyloidogenic pathway (McArthur et al., 1997; Zhu et al., 2001; Hoppe et al., 2010). In vivo studies with transgenic mice over-expressing APP (in 9-10 months they develop senile plaques) and fed with $0.5 \mathrm{mg} / \mathrm{mL}$ of melatonin in their drinking water $(3 \mathrm{~mL} /$ day) found a reduction in important markers of the disease, including $A \beta$ levels in the brain, and that some animals survived (Matsubara et al., 2003). The amount given to rodents are within the pharmacological dose and out of the range of the dose that can be achieved with moderate consumption of wine. Therefore it cannot be concluded that these effect will be observed in humans after wine intake. Further research is required to obtain the evidence at dietary doses.

Furthermore, melatonin exhibits a protective effect on the cholinergic system. In AD patients, a dramatic decrease of acetylcholine has been observed (Francis et al., 1999), which was related to a decrease in enzyme choline acetyltransferase (ChAT) activity and an increase in acetylcholinesterase (AChE) activity (Bieschke et al., 2005). Indeed, AChE inhibitors increase the synaptic levels of acetylcholine, which is why they are used as a treatment for mild to moderate $\mathrm{AD}$. In vivo administration of melatonin in rats ( $50 \mathrm{mg} / \mathrm{kg}$ body weight) has led to significantly reduced AChE activity, with maintenance of calcium levels under conditions of oxidative stress (Masilamoni et al., 2008). Regarding ChAT, melatonin increased its activity, after 4 months of melatonin administration in rats (Feng et al., 2004).

Finally, melatonin reduces $\mathrm{A} \beta$-induced oxidative stress related to reactive oxygen species (ROS) and proinflamatory cytokines, such as IL6 and IL1- $\beta$ in in vivo studies (Masilamoni et al., 2008). As a result of these effects, melatonin protects brain neurons from damage and death by increasing viability in hippocampal neurons and glial cells following treatment with $A \beta 1-40, A \beta 25-40$, and A $\beta 1-28$. Moreover, melatonin prevents the death of murine N2a neuroblastoma and PC12 cells by using A $\beta 25-35$ (Pappolla et al., 1997; Ionov et al., 2011).

There is scarce literature available in relation to the activity of other tryptophan metabolites, with indole 3-acetic acid and tryptophol being the only bioactive molecules reported so far. Morshedi et al. (2007) proved the inhibitory effect of these indole derivatives on the amyloid fibrillation of hen eggwhite lysozyme, which is another model for exploring the amyloidogenic mechanism.

\section{PARKINSON'S DISEASE}

Parkinson's disease is the second most common neurodegenerative disorder. Its diagnosis is based on motor abnormalities, such as resting tremor, bradykinesia, and rigidity (Duvoisin, 1992). Indeed, patients present other non-motor symptoms, such as depression, anxiety, and sleep disorders (Jenner et al., 2013). Only 10\% of patients have a genetic basis, with $90 \%$ being considered sporadic cases. PD is characterized by the degeneration of the subcortical structure of the brain. Specifically, there are significant losses of dopaminergic neurons in the substantia nigra pars compacta (SNpc; Forno, 1996), although other cell populations are also susceptible to the neurodegeneration process.

$\alpha$-Synuclein $(\alpha S)$ is a 140 amino acid and a highly abundant neuronal protein. It is found as a soluble cytoplasmatic protein associated with synaptic vesicles (Iwai et al., 1995). It is thought that it plays a role in neurotransmission and cognitive function. Although its physiological function is uncertain, the pathology is associated with the accumulation of $\alpha \mathrm{S}$ aggregates, which are the main component of Lewy bodies (LBs; Spillantini et al., 1997). LBs are spherical inclusions formed by $\alpha \mathrm{S}$ aggregate (99\%) and other proteins.

Despite the main risk factor being aging, other possible risk factors include mutation in the SNCA (alpha-synuclein gene) and exposure to environmental toxins. The latter are also linked to metabolic abnormalities involving neurotransmitter systems (dopamine, serotonin, GABA, and glutamate), fatty acids, such as arachidonic acid-cascade, oxidative stress and mitochondrial function (Henchcliffe and Beal, 2008; Quinones and KaddurahDaouk, 2009; Kaidanovich-Beilin et al., 2012; Lei and Powers, 2013).

Furthermore, several studies suggest that $\alpha \mathrm{S}$ oligomers and protofibrils are an important factor in neurotoxicity in PD. $\alpha S$ protofibrils cause membrane permeabilization, which alters cellular homeostasis and may activate an apoptotic process (Volles and Lansbury, 2003). Indeed, there is evidence to support the capacity of $\alpha \mathrm{S}$ to inhibit proteosomal activity, which would prevent elimination of misfolded proteins (Giasson and Lee, 2003).

Substantial evidence also suggests that a significant factor in dopaminergic neuronal loss in the PD brain are ROS, which result from dopamine metabolism, low glutathione concentration and high levels of iron and calcium in the SNpc (Jenner and Olanow, 2006). Additionally, the brain contains high concentrations of polyunsaturated fatty acids, which, under oxidative stress, result in lipid peroxidation and generation of toxic products (Liu et al., 2008).

No treatment is currently available for the prevention or cure of PD. However, a combination of L-DOPA and antioxidants has been recommended to reduce the rate of progression of the disease, due to the decrease in dopamine levels and significant increase of oxidative stress commonly concomitant to this type of disorder (Zhu et al., 2004).

Concerning the role of melatonin in PD, several works have reported different mechanisms of action. Lin et al. (2007) demonstrated that melatonin attenuates arsenite-induced apoptosis by reducing aggregated $\alpha$ S levels in rat brains, by means of Western blot analysis. Additionally, Ishido (2007) showed that melatonin inhibits $\alpha S$ assembly, using immunostaining in rat pheochromocytoma cells.

It is also important to highlight that melatonin dosedependently inhibits all steps of the $\alpha \mathrm{S}$ assembly process. Ono et al. (2012) observed a reduction in the number of fibrils and the corresponding increase of the number of 
short fibrils and amorphous aggregates (25-250 $\mu \mathrm{M})$ using electron microscopy and thioflavin $\mathrm{S}$ experiments. Indeed, melatonin presents a significant destabilization effect (also dosedependently), suggesting a decrease in beta-sheet levels. In the same study, the authors performed experiments with primary cultures of mesencephalon and neostriatum with MTT: (3(4,5-Dimethylthiazol-2-yl)-2,5-Diphenyltetrazolium Bromide) a colorimetric assay for assessing cell metabolic activity. The results showed that melatonin reduced the toxic effects of $\alpha S$ after pretreatment (2-6 days) with an increase in cell viability of between 56 and $97 \%$.

In addition to this, it is well known that melatonin exhibits antioxidant properties (Reiter et al., 1997; Kotler et al., 1998). Cellular injury cause by $\alpha$ S-mediated perturbation of cellular redox reactions is an important mechanism proposed for $\mathrm{PD}$ (George et al., 2009). Melatonin has been suggested as a potential therapeutic agent in diseases where oxidative stress is thought to be a major pathogenic factor. Mayo et al. (1998) observed that this hormone was an effective free radical scavenger and that it prevented apoptosis in neuronal cells. Moreover, in vitro studies on MPTD-induced (1-methyl4-phenyl-1,2,3,6-tetrahydropyridine) $\mathrm{PD}$ in mice have shown that melatonin protects against excitotoxicity by reducing the autoxidation of dopamine. The administration of melatonin leads

\section{REFERENCES}

Abramov, A. Y., Canevar, L., and Duchen, M. R. (2003). Changes in intracellular calcium and glutathione in astrocytes as the primary mechanism of amyloid neurotoxicity. J. Neurosci. 23, 5088-5095.

Abramov, A. Y., Canevari, L., and Duchen, M. R. (2004). Beta-amyloid peptides induce mitochondrial dysfunction and oxidative stress in astrocytes and death of neurons through activation of NADPH oxidase. J. Neurosci. 24, 565-575. doi: 10.1523/JNEUROSCI.4042-03.2004

Abramov, A. Y., and Duchen, M. R. (2005). The role of an astrocytic NADPH oxidase in the nurotoxicity of amyloid beta peptides. Philos. Trans. R. Soc. Lond. B Biol. Sci. 360, 2309-2314. doi: 10.1098/rstb.2005.1766

Abramov, A. Y., Fraley, C., Diao, C. T., Winkfein, R., Colicos, M. A., Duchen, M. R., et al. (2007). Targeted polyphosphatase expression alters mitochondrial metabolism and inhibits calcium-dependent cell death. Proc. Natl. Acad. Sci. U.S.A. 104, 18091-18096. doi: 10.1073/pnas.0708959104

Álvarez-García, V., González, A., Alonso-González, C., Martínez-Campa, C., and Cos, S. (2013). Regulation of vascular endothelial growth factor by melatonin in human breast cancer cells. J. Pineal Res. 54, 373-380. doi: 10.1111/jpi.12007

Bartolomé, B., Pena-Neira, A., and Gomez-Cordoves, C. (2000). Phenolics and related substances in alcohol-free beers. Eur. Food Res. Technol. 210, 419-423. doi: 10.1007/s002170050574

Behl, C., Davis, J. B., Lesley, R., and Schubert, D. (1994). Hydrogen peroxide mediates amyloid beta protein toxicity. Cell 77, 817-827. doi: 10.1016/00928674(94)90131-7

Bergers, G., and Benjamin, L. E. (2003). Tumorigenesis and the angiogenic switch. Nat. Rev. Cancer. 3, 401-410. doi: 10.1038/nrc1093

Bezprozvanny, I., and Mattson, M. P. (2008). Neuronal calcium mishandling and the pathogenesis of Alzheimer's disease. Trends Neurosci. 31, 454-463. doi: 10.1016/j.tins.2008.06.005

Bieschke, J., Zhang, Q., Powers, E. T., Lerner, R. A., and Kelly, J. W. (2005). Oxidative metabolites accelerate Alzheimer's amyloidogenesis by a two-step mechanism, eliminating the requirement for nucleation. Biochemistry 44, 49774983. doi: 10.1021/bi0501030

Cebe-Suarez, S., Zehnder-Fjallman, A., and Ballmer-Hofer, K. (2006). The role of VEGF receptors in angiogenesis; complex partnerships. Cell. Mol. Life Sci. 63, 601-615. doi: 10.1007/s00018-005-5426-3 to normalization of complex I activity and oxidative status in mitochondria (Escames et al., 2010).

In conclusion, and based on the preceding evidence, we should consider that melatonin presents strong inhibitory effects on protofibril formation and peptide oligomerization.

\section{AUTHOR CONTRIBUTIONS}

RH-O and AC Literature search and first draft. AT, MG-P, and AM thorough revision and discussion and final document.

\section{FUNDING}

This work was supported by the Ministry of Economy and Competitiveness, Spain (grant no. AGL2013-47300-C1 and AGL2013-47300-C3).

\section{ACKNOWLEDGMENTS}

We acknowledge the Universidad de Sevilla for the contracts of $\mathrm{AC}$ and RH-O.

Celletti, F. L., Waugh, J. M., Amabile, P. G., Brendolan, A., Hilfiker, P. R., and Dake, M. D. (2001). Vascular endothelial growth factor enhances atherosclerotic plaque progression. Nat. Med. 7, 425-429. doi: 10.1038/86490

Cook, K. M., and Figg, W. D. (2010). Angiogenesis inhibitors: current strategies and future prospects. CA-Cancer J. Clin. 60, 222-243. doi: 10.3322/caac. 20075

Cui, P., Yu, M., Luo, Z., Dai, M., Han, J., Xiu, R., et al. (2008). Intracellular signaling pathways involved in cell growth inhibition of human umbilical vein endothelial cells by melatonin. J. Pineal Res. 44, 107-114. doi: 10.1111/j.1600079X.2007.00496.x

Cui, P., Yu, M., Peng, X., Dong, L., and Yang, Z. (2012). Melatonin prevents human pancreatic carcinoma cell PANC-1-induced human umbilical vein endothelial cell proliferation and migration by inhibiting vascular endothelial growth factor expression. J. Pineal Res. 52, 236-243. doi: 10.1111/j.1600-079X.2011. 00933.x

Dai, M., Cui, P., Yu, M., Han, J., Li, H., and Xiu, R. (2008). Melatonin modulates the expression of VEGF and HIF- $1 \alpha$ induced by $\mathrm{CoCl} 2$ in cultured cancer cells. J. Pineal Res. 44, 121-126. doi: 10.1111/j.1600-079X.2007.00498.x

de Almeida, E. A., Di Mascio, P., Harumi, T., Spence, D. W., Moscovitch, A., Hardeland, R., et al. (2011). Measurement of melatonin in body fluids: standards, protocols and procedures. Childs Nerv. Syst. 27, 879-891. doi: 10.1007/s00381-010-1278-8

Dulak, J. (2005). Nutraceuticals as anti-angiogenic agents: hopes and reality. J. Physiol. Pharmacol. 1, 51-67.

Duvoisin, R. C. (1992). Overview of Parkinsonś disease Ann. N. Y. Acad. Sci. 648, 187-193. doi: 10.1111/j.1749-6632.1992.tb24537.x

Escames, G., López, A., García, J. A., García, L., Acuña-Castroviejo, D., García, J. J., et al. (2010). The role of mitocondria in brain aging and the effects of melatonin. Curr. Neuropharmacol. 8, 182-193. doi: 10.2174/157015910792246245

Feng, Z., Chang, Y., Cheng, Y., Zhang, B. L., Qu, Z. W., Qin, C., et al. (2004). Melatonin alleviates behavioral deficits associated with apoptosis and cholinergic system dysfunction in the APP 695 transgenic mouse model of Alzheimerś disease. J. Pineal Res. 37, 129-136. doi: 10.1111/j.1600079X.2004.00144.x

Fernández-Pachón, M. S., Medina, S., Herrero-Martín, G., Cerrillo, I., Berná, G., Escudero-López, B., et al. (2014). Alcoholic fermentation induces melatonin synthesis in orange juice. J. Pineal Res. 56, 31-38. doi: 10.1111/jpi.12093 
Ferrara, N., and Kerbel, R. S. (2005). Angiogenesis as a therapeutic target. Nature 438, 967-974. doi: 10.1038 /nature 04483

Forno, L. S. (1996). Neuropathology of Parkinsonś disease. J. Neurophatol. Exp. Neurol. 55, 259-272. doi: 10.1097/00005072-199603000-00001

Francis, P. T., Palmer, A. M., Snape, M., and Wilcock, G. K. (1999). The cholinergic hypothesis of Alzheimers disease: a review of progress. J. Neurol. Neurosurg. Psychiatry 66, 137-147. doi: 10.1136/jnnp.66.2.137

Fraser, P. E., Nguyen, J. T., Surewicz, W. K., and Kirschner, D. A. (1991). pHdependent structural transitions of Alzheimer's amyloid peptides. Biophys. J. 60, $1190-1201$.

Gandy, S. (2005). The role of cerebral amyloid $\beta$ accumulation in common forms of Alzheimer disesase. J. Clin. Invest. 115, 1121-1129. doi: 10.1172/JCI2005 25100

George, J. L., Mok, S., Moses, D., Wilkins, S., Bush, A. I., Cherny, R. A., et al. (2009). Targeting the progression of Parkinson's disease. Curr. Neuropharmacol. 7, 9-36. doi: 10.2174/157015909787602814

Giasson, B., and Lee, V. M. (2003). Are ubiquitination pathways central to Parkinson's disease? Cell 114, 1-8. doi: 10.1016/S0092-8674(03)00509-9

Giles, F. J. (2001). The vascular endothelial growth factor (VEGF) signaling pathway: a therapeutic target in patients with hematologic malignancies. Oncologist 6, 32-39. doi: 10.1634/theoncologist.6-suppl_5-32

Gonçalves, N. N., Rodrigues, R. V., Jardim-Perassi, B. V., Moschetta, M. G., Lopes, J. R., Colombo, J., et al. (2014). Molecular markers of angiogenesis and metastasis in lines of oral carcinoma after treatment with melatonin. Anti Cancer Agents Med. Chem. 14, 1302-1311. doi: 10.2174/187152061 4666140812110246

Greilberger, J., Fuchs, D., Leblhuber, F., Greilberger, M., Wintersteiger, R., and Tafeit, E. (2010). Carbonyl proteins as a clinical marker in Alzheimers disease and its relation to tryptophan degradation and immune activation. Clin. Lab. $56,441-448$.

Hamel, E., Nicolakakis, N., Aboulkassim, T., Ongali, B., and Tong, X. K. (2008). Oxidative stress and cerebrovascular dysfunction in mouse models of Alzheimerś disease. Exp. Physiol. 93, 116-120. doi: 10.1113/expphysiol. 2007.038729

Hardy, J., and Selkoe, D. J. (2002). The amyloid hypothesis of Alzheimerśdisease: progress and problems on the road to therapeutics. Science 297, 353-356. doi: 10.1126/science. 1072994

Harpsøe, N. G., Andersen, L. P., Gögenurm, I., and Rosenberg, J. (2015). Clinical pharmacokinetics of melatonin: a systematic review. Eur. J. Clin. Pharmacol. 71, 901-909. doi: 10.1007/s00228-015-1873-4

Henchcliffe, C., and Beal, M. F. (2008). Mitochondrial biology and oxidative stress in Parkinson disease pathogenesis. Nat. Clin. Pract. Neurol. 4, 600-609. doi: 10.1038/ncpneuro0924

Hoppe, J. B., Frozza, R. L., Horn, A. P., Comiran, R. A., Bernardi, A., Campos, M. M., et al. (2010). Amyloid-beta neurotoxicity in organotypic culture is attenuated by melatonin: involvement of GSK-3beta, tau and neuroinflammation. J. Pineal Res. 48, 230-238. doi: 10.1111/j.1600-079X. 2010.00747.x

Huang, T. H., Fraser, P. E., and Chakrabartty, A. (1997). Fibrillogenesis of Alzheimer's Abeta peptides studied by fluorescence energy transfer. J. Mol. Biol. 269, 214-224. doi: 10.1006/jmbi.1997.1050

Husson, I., Mesples, B., Bac, P., Vamecq, J., Evrard, P., and Gressens, P. (2002). Melatoninergic neuroprotection of the murine periventricular white matter against neonatal excitotoxic challenge. Ann. Neurol. 51, 82-92. doi: 10.1002/ana.10072

Ionov, M., Burchell, V., Klajnert, B., Bryszewska, M., and Abramov, A. Y. (2011). Mechanism of neuroprotection of melatonin against betaamyloid neurotoxicity. Neuroscience 180, 229-237. doi: 10.1016/j. neuroscience.2011.02.045

Ishido, M. (2007). Melatonin inhibits maneb-induced aggregation of alphasynuclein in rat pheochromocytoma cells. J. Pineal Res. 42, 125-130. doi: 10.1111/j.1600-079X.2006.00390.x

Iwai, A., Masliah, E., Yoshimoto, M., Ge, N., Flanagan, L., de Silva, H. A. R., et al. (1995). The precursor protein of non- $A \beta$ component of Alzheimer's disease amyloid is a presynaptic protein of the central nervous system. Neuron 14 , 467-475. doi: 10.1016/0896-6273(95)90302-X

Jardim-Perassi, B. V., Arbab, A. S., Ferreira, L. C., Borin, T. F., Varma, N. R. S., Iskander, A. S. M., et al. (2014). Effect of melatonin on tumor growth and angiogenesis in xenograft model of breast Cancer. PLoS ONE 9:e85311. doi: 10.1371/journal.pone.0085311

Jenner, P., Morris, H. R., Robbins, T. W., Goedert, M., Hardy, J., Ben-Shlomo, Y., et al. (2013). Parkinson's disease-the debate on the clinical phenomenology, aetiology, pathology and pathogenesis. J. Parkinson's Dis. 3, 1-11. doi: 10.3233/JPD-130175

Jenner, P., and Olanow, W. (2006). The pathogenesis of cell death in Parkinson's disease. Neurology 66, S24-S36. doi: 10.1212/WNL.66.10_suppl_4.S24

Jiang, D., and Peterson, D. G. (2013). Identification of bitter compounds in whole wheat bread. Food Chem. 141, 1345-1353. doi: 10.1016/j.foodchem.2013. 03.021

Kaidanovich-Beilin, O., Cha, D. S., and McIntyre, R. S. (2012). Crosstalk between metabolic and neuropsychiatric disorders. F1000 Biol. Repl. 4:14. doi: 10.3410/B4-14

Kappers, M. H. W., Smedts, F. M. M., Horn, T., van Esch, J. H. M., Sleijfer, S., Leijten, F., et al. (2010). Hypertension induced by the tyrosine kinase inhibitor sunitinib is associated with increased circulating endothelin-1 levels. Hypertension 56, 675-681. doi: 10.1161/HYPERTENSIONAHA.109.149690

Khurana, R., Simons, M., Martin, J. F., and Zachary, I. C. (2005). Role of angiogenesis in cardiovascular disease - A critical appraisal. Circulation 112, 1813-1824. doi: 10.1161/CIRCULATIONAHA.105.535294

Kirschbaum, J., Meier, A., and Brtickner, H. (1999). Determination of biogenic amines in fermented beverages and vinegars by pre-column derivatization with para-Nitrobenzyloxycarbonyl Chloride (PNZ-CI) and Reversed-Phase LC. Chromatographia 49, 117-124. doi: 10.1007/BF02575272

Kocadağli, T., Yilmaz, C., and Gökmen, V. (2014). Determination of melatonin and its isomer in foods by liquid chromatography tandem mass spectrometry. Food Chem. 153, 151-156. doi: 10.1016/j.foodchem.2013.12.036

Kotler, M., Rodríguez, C., Sáinz, R. M., Antolín, I., and Menéndez-Peláez, A. (1998). Melatonin increases gene expression for antioxidant enzymes in rat brain cortex. J. Pineal Res. 24, 83-89. doi: 10.1111/j.1600-079X.1998.tb00371.x

Lahiri, D. K. (1999). Melatonin affects the metabolism of the beta-amyloid precursor protein in different cell types. J. Pineal. Res. 26, 137-146. doi: 10.1111/j.1600-079X.1999.tb00575.x

Lashuel, H. A., Petre, B. M., Wall, J., Simon, M., Nowak, R. J., Walz, T., et al. (2002). $\alpha$-synuclein, especially the Parkinson's disease- associated mutants, forms pore-like annular and tubular protofibrils. J. Mol. Biol. 322, 1089-1102. doi: 10.1016/S0022-2836(02)00735

Lei, S., and Powers, R. (2013). NMR metabolomics analysis of Parkinson's Disease. Curr. Metabolomics. 1, 191-209. doi: 10.2174/2213235X113019990004

Lin, A. M., Fang, S. F., Chao, P. L., and Yang, C. H. (2007). Melatonin attenuates arsenite-induced apoptosis in rat brain: involvement of mitochondrial and endoplasmic reticulum pathways and aggregation of alpha-synuclein. J. Pineal Res. 43, 163-171. doi: 10.1111/j.1600-079X.2007.00456.x

Lissoni, P., Rovelli, F., Malugani, F., Bucovec, R., Conti, A., and Maestroni, G. J. M. (2001). Anti-angiogenic activity of melatonin in advanced cancer patients. Neurol. Endocrinol. Lett. 22, 45-47.

Liu, X., Yamada, N., Maruyama, W., and Osawa, T. (2008). Formation of dopamine adducts derived from brain polyunsaturated fatty acids: mechanism for Parkinson disease. J. Biol. Chem. 283, 34887-34895. doi: 10.1074/jbc.M805682200

Maldonado, M. D., Moreno, H., and Calvo, J. R. (2009). Melatonin present in beer contributes to increase the levels of melatonin and antioxidant capacity of the human serum. Clin. Nutr. 28, 188-191. doi: 10.1016/j.clnu.2009.02.001

Mandrioli, R., Morganti, E., Mercolini, L., Kenndler, E., and Raggi, M. A. (2011). Fast analysis of amino acids in wine by capillary electrophoresis with laser-induced fluorescence detection. Electrophoresis 32, 2809-2815. doi: 10.1002/elps.201100112

Manfroi, L., Silva, P. H. A., Rizzonc, L. A., Sabainid, P. S., and Glória, M. B. A. (2009). Influence of alcoholic and malolactic starter cultures on bioactive amines in Merlot wines. Food Chem. 116, 208-213. doi: 10.1016/j.foodchem.2009.02.034

Mas, A., Guillamon, J. M., Torija, M. J., Beltran, G., Cerezo, A. B. A. M., Troncoso, A. M., et al. (2014). Bioactive compounds derived from the yeast metabolism of aromatic amino acids during alcoholic fermentation. Biomed. Res. Int. 7. doi: $10.1155 / 2014 / 898045$

Masilamoni, J. G., Jesudason, E. P., Dhandayuthapani, S., Ashok, B. S., Vignesh, S., Jebaraj, W. C., et al. (2008). The neuroprotective role of melatonin against 
amyloid beta peptide injected mice. Free Radic. Res. 42, 661-673. doi: 10.1080/10715760802277388

Matsubara, E., Bryant-Thomas, T., Pacheco Quinto, J., Henry, T. L., Poeggeler, B., Herbert, D., et al. (2003). Melatonin increases survival and inhibits oxidative and amyloid pathology in a transgenic model of Alzheimer's disease. J. Neurochem. 85, 1101-1108. doi: 10.1046/j.1471-4159.2003.01654.x

Mayo, J. C., Sainz, R. M., Uria, H., Antolin, I., Esteban, M. M., and Rodriguez, C. (1998). Melatonin induced by 6-hydroxydopamine in neuronal cells: implications for Parkinson's disease. J. Pineal Res. 24, 179-192. doi: 10.1111/j.1600-079X.1998.tb00531.x

McArthur, A. J., Hunt, A. E., and Gillette, M. U. (1997). Melatonin action and signal transduction in the rat suprachiasmatic circadian clock: activation of protein kinase C at dusk and dawn. Endocrinology 138, 627-634. doi: 10.1210/endo.138.2.4925

McNaull, B. B., Todd, S., McGuinness, B., and Passmore, A. P. (2010). Inflammation and anti-inflammatory strategies for Alzheimer's disease-a mini-review. Gerontology 56, 3-14. doi: 10.1159/000237873

Mercolini, L., Mandrioli, R., and Raggi, M. A. (2012). Content of melatonin and other antioxidants in grape-related foodstuffs: measurement using a MEPS-HPLC-F method. J. Pineal Res. 53, 21-28. doi: 10.1111/j.1600079X.2011.00967.x

Monagas, M., Gomez-Cordoves, C., and Bartolome, B. (2007). Evaluation of different Saccharomyces cerevisiae strains for red winemaking. Influence on the anthocyanin, pyranoanthocyanin and non-anthocyanin phenolic content and colour characteristics of wines. Food Chem. 104, 814-823. doi: 10.1016/j.foodchem.2006.12.043

Moreira, P. I., Carvalho, C., Zhu, X., Smith, M. A., and Perry, G. (2010). Mitochondrial dysfunction is a trigger of Alzheimer's disease pathophysiology. Biochim. Biophys. Acta 1802, 2-10. doi: 10.1016/j.bbadis.2009.10.006

Moreira, P. I., Santos, M., Moreno, A. J. M., and Oliveira, C. (2001). Amyloid betapeptide promotes permeability transition pore in brain mitochondria. Biosci. Rep. 21, 789-800. doi: 10.1023/A:1015536808304

Morshedi, D., Rezaei-Ghaleh, N., Ebrahim-Habibi, A., Ahmadian, S., and NematGorgani, M. (2007). Inhibition of amyloid fibrillation of lysozyme by indole derivatives - possible mechanism of action. FEBS J. 274, 6415-6425. doi: 10.1111/j.1742-4658.2007.06158.x

Moyle, C. W. A., Cerezo, A. B., Winterbone, M. S., Hollands, W. J., Alexeev, Y., Needs, P. W., et al. (2015). Potent inhibition of VEGFR-2 activation by tight binding of green tea epigallocatechin gallate and apple procyanidins to VEGF: relevance to angiogenesis. Mol. Nutr. Food Res. 59, 401-412. doi: $10.1002 / \mathrm{mnfr} .201400478$

Ono, K., Mochizuki, H., Ikeda, T., Nihira, T., Takasaki, J., Teplow, D. B., et al. (2012). Effect of melatonin on $\alpha$-synuclein self-assembly and cytotoxicity. Neurobiol. Aging 33, 2172-2185. doi: 10.1016/j.neurobiolaging.2011.10.015

Outeiro, T. F., Putcha, P., Tetzlaff, J. E., Spoelgen, R., Koker, M., Carvalho, F., et al. (2008). Formation of toxic oligomeric $\alpha$-synuclein species in living cells. PLoS ONE 3:e1867. doi: 10.1371/journal.pone.0001867

Pappolla, M., Bozner, P., Soto, C., Shao, H., Robakis, N. K., Zagorski, M., et al. (1998). Inhibition of Alzheimer beta-fibrillogenesis by melatonin. J. Biol. Chem. 273, 7185-7188. doi: 10.1074/jbc.273.13.7185

Pappolla, M. A., Sos, M., Omar, R. A., Bick, R. J., Hickson-Bick, D. L., Reiter, R. J., et al. (1997). Melatonin prevents death of neuroblastoma cells exposed to the Alzheimer amyloid peptide. J. Neurosci. 17, 1683-1690.

Persidsky, Y. G., and Potula, R. (2014). “Alcohol and neurodegeneration,” in Neuroinflammation and Neurodegeneration, ed. P.K. Peterson and M. Toborek (New York, NY: Springer), 511-526.

Pike, C. J., Burdick, D., Walencewicz, A. J., Glabe, C. G., and Cotman, C. W. (1993). Neurodegeneration induced by beta-amyloid peptides in vitro: the role of peptide assembly state. J. Neurosci. 13, 1676-1687.

Quinones, M. P., and Kaddurah-Daouk, R. (2009). Metabolomics tools for identifying biomarkers for neuropsychiatric diseases. Neurobiol. Dis. 35, 165176. doi: 10.1016/j.nbd.2009.02.019

Reiter, R., Tang, L., Garcia, J. J., and Muñoz-Hoyos, A. (1997). Pharmacological actions of melatonin in oxygen radical pathophysiology. Life Sci. 60, 2255-2271. doi: 10.1016/S0024-3205(97)00030-1

Rodriguez-Naranjo, M. I., Gil-Izquierdo, A., Troncoso, A. M., Cantos-Villar, E., and Garcia-Parrilla, M. C. (2011). Melatonin is synthesised by yeast during alcoholic fermentation in wines. Food Chem. 126, 1608-1613. doi: 10.1016/j.foodchem.2010.12.038
Rodriguez-Naranjo, M. I., Torija, M. J., Mas, A., Cantos-Villar, E., and GarciaParrilla, M. C. (2012). Production of melatonin by Saccharomyces strains under growth and fermentation conditions. J. Pineal Res. 53, 219-224. doi: 10.1111/j.1600-079X.2012.00990.x

Senger, D. R., Van De Water, L., Brown, L. F., Nagy, J. A., Yeo, K. T., Yeo, T. K., et al. (1993). Vascular permeability factor (VPF, VEGF) in tumor biology. Cancer Metast. Rev. 12, 303-324. doi: 10.1007/BF00665960

Skribanek, Z., Balaspiri, L., and Mak, M. (2001). Interaction between synthetic amyloid-beta-peptide (1-40) and its aggregation inhibitors studied by electrospray ionization mass spectrometry. J. Mass Spectrom. 36, 1226-1229. doi: $10.1002 /$ jms. 243

Sohn, E. J., Won, G., Lee, L., Lee, S., and Kim, S. H. (2015). Upregulation of miRNA3195 and miRNA374b mediates the anti-angiogenic properties of melatonin in hypoxic PC-3 prostate cancer cells. J. Cancer. 6, 19-28. doi: 10.7150/jca.9591

Song, W., and Lahiri, D. K. (1997). Melatonin alters the metabolism of the beta-amyloid precursor protein in the neuroendocrine cell line PC12. J. Mol. Neurosci. 9, 75-92. doi: 10.1007/BF02736852

Spillantini, M. G., Schmidt, M. L., Lee, V. M.-Y., Trojanowski, J. Q., Ross, J., and Michel, G. M. (1997). $\alpha$-Synuclein in Lewy bodies. Nature 388, 839-840. doi: $10.1038 / 42166$

Sprague, G. F. Jr., and Winans, S. C. (2006). Eukaryotes learn how to count: quorum sensing by yeast. Genes Dev. 20, 1045-1049. doi: 10.1101/gad.1432906

Stege, P. W., Sombra, L. L., Messina, G., Martinez, L. D., and Silva, M. F. (2010). Determination of melatonin in wine and plant extracts by capillary electrochromatography with immobilized carboxylic multi-walled carbon nanotubes as stationary phase. Electrophoresis 31, 2242-2248. doi: 10.1002/elps.200900782

Vitalini, S., Gardana, C., Simonetti, P., Fico, G., and Iriti, M. (2013). Melatonin, melatonin isomers and stilbenes in Italian traditional grape products and their antiradical capacity. J. Pineal Res. 54, 322-333. doi: 10.1111/jpi.12028

Volles, M. J., and Lansbury, P. T. Jr. (2003). Zeroing in on the pathogenic form of alpha-synuclein and its mechanism of neurotoxicity in Parkinson's Disease. Biochemistry 42, 7871-7878. doi: 10.1021/bi030086j

Wang, Y. Q., Ye, D. O., Zhu, B. Q., Wu, G. F., and Duan, C. Q. (2014). Rapid HPLC analysis of amino acids and biogenic amines in wines during fermentation and evaluation of matrix effect. Food Chem. 163, 6-15. doi: 10.1016/j.foodchem.2014.04.064

Wu, S., Chen, J. J., Kudelka, A., Lu, J., and Zhu, X. (2008). Incidence and risk of hypertension with sorafenib in patients with cancer: a systematic review and meta-analysis. Lancet Oncol. 9, 117-123. doi: 10.1016/S1470-2045(08) 70003-2

Zhou, J. N., Liu, R. Y., Kamphorst, W., Hofman, M. A., and Swaab, D. F. (2003). Early neuropathological Alzheimers changes in aged individuals are accompanied by decreased cerebrospinal fluid melatonin levels. J. Pineal Res. 35, 125-130. doi: 10.1034/j.1600-079X.2003.00065.x

Zhu, G., Wang, D., Lin, Y. H., McMahon, T., Koo, E. H., and Messing, R. O. (2001). Protein kinase C epsilon suppresses Abeta production and promotes activation of alphasecretase. Biochem. Biophys. Res. Commun. 285, 997-1006. doi: 10.1006/bbrc.2001.5273

Zhu, M., Rajamani, S., Kaylor, J., Han, S., Zhou, F., and Fink, A. L. (2004). The flavonoid baicalein inhibits fibrillation of alpha-synucleinand disaggregates existing fibrils. J Biol. Chem. 279, 26846-26857. doi: 10.1074/jbc.M403129200

Zhu, X., Wu, S., Dahut, W. L., and Parikh, C. R. (2007). Risks of Proteinuria and hypertension with Bevacizumab, an antibody against vascular endothelial growth factor: systematic Review and meta-analysis. Am. J. Kidney Dis. 49, 186-193. doi: 10.1053/j.ajkd.2006.11.039

Conflict of Interest Statement: The authors declare that the research was conducted in the absence of any commercial or financial relationships that could be construed as a potential conflict of interest.

Copyright (c) 2016 Hornedo-Ortega, Cerezo, Troncoso, Garcia-Parrilla and Mas. This is an open-access article distributed under the terms of the Creative Commons Attribution License (CC BY). The use, distribution or reproduction in other forums is permitted, provided the original author(s) or licensor are credited and that the original publication in this journal is cited, in accordance with accepted academic practice. No use, distribution or reproduction is permitted which does not comply with these terms. 